\title{
Landscape-scale changes in forest structure and functional traits along an Andes-to-Amazon elevation gradient
}

\author{
G. P. Asner ${ }^{1}$, C. B. Anderson ${ }^{1}$, R. E. Martin ${ }^{1}$, D. E. Knapp ${ }^{1}$, R. Tupayachi ${ }^{1}$, F. Sinca ${ }^{1}$, and Y. Malhi ${ }^{2}$ \\ ${ }^{1}$ Department of Global Ecology, Carnegie Institution for Science, 260 Panama Street, Stanford CA 94305, USA \\ ${ }^{2}$ School of Environment and Geography, University of Oxford, South Parks Road, Oxford OX1 3QY, UK
}

Correspondence to: G. P. Asner (gpa@carnegiescience.edu)

Received: 17 August 2013 - Published in Biogeosciences Discuss.: 27 September 2013

Revised: 8 January 2014 - Accepted: 9 January 2014 - Published: 11 February 2014

\begin{abstract}
Elevation gradients provide opportunities to explore environmental controls on forest structure and functioning. We used airborne imaging spectroscopy and lidar (light detection and ranging) to quantify changes in threedimensional forest structure and canopy functional traits in twenty 25 ha landscapes distributed along a $3300 \mathrm{~m}$ elevation gradient from lowland Amazonia to treeline in the Peruvian Andes. Elevation was positively correlated with lidar-estimated canopy gap density and understory vegetation cover, and negatively related to canopy height and the vertical partitioning of vegetation in canopies. Increases in canopy gap density were tightly linked to increases in understory plant cover, and larger gaps $\left(20-200 \mathrm{~m}^{2}\right)$ produced $25-$ 30 times the response in understory cover than did smaller gaps $\left(<5 \mathrm{~m}^{2}\right)$. Vegetation NDVI and photosynthetic fractional cover decreased, while exposed non-photosynthetic vegetation and bare soil increased, with elevation. Scaling of gap size to gap frequency $(\lambda)$ was, however, nearly constant along the elevation gradient. When combined with other canopy structural and functional trait information, this suggests near-constant canopy turnover rates from the lowlands to treeline, which occurs independent of decreasing biomass or productivity with increasing elevation. Our results provide the first landscape-scale quantification of forest structure and canopy functional traits with changing elevation, thereby improving our understanding of disturbance, demography and ecosystem processes in the Andes-to-Amazon corridor.
\end{abstract}

\section{Introduction}

Tropical elevation gradients offer natural laboratories for studies of environmental controls on forest composition, structural habitats, functional processes, and ecosystem development (Vitousek et al., 1992). Studies to date have used field-based observations to quantify elevation-related changes in nutrient cycling, productivity and a variety of plant traits (e.g., Alves et al., 2010). Results often show that species composition changes markedly with increasing elevation in the tropics (Silman, 2006; Lieberman et al., 1996), yet patterns of canopy functional traits and productivity have been much more variable (e.g., Vitousek et al., 1988; Raich et al., 1997; Girardin et al., 2010). Indeed, field-based elevation studies report wide-ranging results that are challenging to synthesize into generalizable patterns and emergent principles (Tanner et al., 1998; Hodkinson, 2005).

While reports on elevation-based changes in functional traits vary widely in the tropics, patterns of and the processes underlying forest canopy structure such as volume, canopy layering and gap dynamics remain even less understood. Yet canopy structure expresses the outcome of, and mediates the future of, functional processes such as light use, turnover and net primary productivity, or NPP (Asner et al., 1998; Brokaw, 1985b). Structure also creates the habitat for all other forestdwelling species (Terborgh, 1992), so a quantitative understanding of canopy structural change with elevation underpins conservation and management planning.

A significant problem limiting our understanding of elevational patterns of forest functional and structural properties rests in accessing remote field sites and canopies. In most cases, sub-montane to montane forests have proven the most 
difficult to study, owing to rough terrain, poor road and river access, and arduous overland distances. Another problem centers on ecological scale; perhaps every study thus far published on elevation-related changes in tropical forest properties has focused either on individual species or in plots no larger than a hectare. Yet habitats vary locally at any given elevation, simply based on slope, aspect and disturbance. This hampers efforts to determine the average effects of elevation on canopy structural properties and functional processes.

Remote sensing offers to overcome the limits of field work by providing measurements of forests at larger geographic scales. However, persistent cloud cover common to tropical mountains severely limits the utility of satellite-based observations (Ticehurst et al., 2004). Airborne platforms offer a solution because the measurements can be planned around local cloud cover dynamics. More importantly, airborne techniques offer far more biophysical and functional trait information than do current satellite-based approaches. Forest functional traits, including light interception, foliar cover and canopy chemistry, are often reported using hyperspectral data collected with imaging spectrometers (reviews by Kokaly et al., 2009; Ustin et al., 2004). Forest canopy structure is increasingly being explored using airborne Light Detection and Ranging (lidar) systems (Lefsky et al., 2002; Drake et al., 2002). Combined, imaging spectroscopy and lidar represent a powerful approach, providing uniquely high data dimensionality required to probe the composition, structure and functioning of ecosystems (Asner et al., 2012b). However, these newer technologies have not been applied to tropical elevation gradients.

The Andes-to-Amazon corridor stretches $2000 \mathrm{~km}$ from Colombia to Bolivia, and from elevations of $\sim 100 \mathrm{~m}$ in the Amazon lowlands to nearly $4000 \mathrm{~m}$ at the Andean treeline. The forest canopy is comprised of thousands of plant species arranged in communities associated with changing elevation, geology, soils and hydrological conditions (Gentry, 1988). To date, most studies of forest functional and structural patterns have focused on the Amazon lowlands, demonstrating that forest canopy height, aboveground biomass and foliar nutrient concentrations vary by community, soil type and geologic substrate (Quesada et al., 2012; Baker et al., 2004; Fyllas et al., 2009; Asner et al., 2010). A recent study also found that canopy gap-size frequency distributions - a quantitative expression of turnover patterns - are surprisingly constant throughout the southwestern Amazonian lowlands (Asner et al., 2013).

In comparison to the lowlands, we have little knowledge of canopy structural and functional variation along elevation gradients up to the Andean treeline. Recent plot-based studies suggest that aboveground biomass decreases with increasing altitude, and NPP declines at elevations above 1500 m a.s.l. (Girardin et al., 2010; Huaraca Huasco et al., 2014; Moser et al., 2011). This occurs despite the fact that leaf area index (LAI) and photosynthetic capacity $\left(A_{\max }\right)$ remain fairly constant, thus pointing to decreased energy inputs (cloud cover) and temperature-lowering carbon uptake at higher elevations (Y. Malhi, unpublished data). Decreasing biomass paralleled by decreasing productivity also suggests nearly constant residence time, as reported by Girardin et al. (2014). If true, this should be reflected in near-constant patterns of canopy gap formation along elevation gradients, but this has not yet been assessed.

We quantified landscape-scale changes in forest canopy structural and functional properties from lowland Amazonia to the Andean treeline in Peru. Our assessment was carried out at an ecological scale thus far unachieved in the field - 25 ha forest landscapes in 20 unique abiotic settings described by varying elevation, climate and soils. We used the Carnegie Airborne Observatory (CAO) Airborne Taxonomic Mapping System (AToMS) to collect multi-dimensional measurements of vegetation (Asner et al., 2012b), and to answer these questions: (i) How do canopy height and the vertical partitioning of the vegetation change with elevation? (ii) Do canopy gaps co-vary with changes in canopy structure along the elevation gradient? (iii) How do canopy functional traits such as light interception, photosynthetic and non-photosynthetic vegetation cover, and greenness change with elevation? (iv) Do structural and functional traits covary with one another, and if so, how does elevation affect relationships between traits? (v) Do remotely sensed canopy properties corroborate plot-based suggestions of nearly constant biomass turnover along an Andes-to-Amazon elevation gradient?

\section{Methods}

\subsection{Study landscapes}

Twenty study landscapes, each 25 ha in size, were selected for sampling parts of northern, central and southern Peru (Table 1), centered mainly around 1 ha plots that have previously been used for forest inventories (Peacock et al., 2007), and/or intensive carbon budget analysis (Malhi et al., 2010). In these landscapes, mean annual precipitation ranges from 1705 to $5020 \mathrm{~mm} \mathrm{yr}^{-1}$. Mean annual temperature varies from $8.0^{\circ} \mathrm{C}$ at the highest elevation sites in the Andes to $26.6^{\circ} \mathrm{C}$ in the warmest lowland site. Soils in the lowland landscapes vary among three broad classes: Ultisols on terra firme clay substrates, Inceptisols on inactive high-fertility floodplains of late Holocene age, and Entisols in two locales in northern Peru. These Entisols are white sand substrates associated with very low nutrient availability (Fine et al., 2004). In the Andean landscapes, soils are classified as Inceptisols or welldeveloped Entisols (Quesada et al., 2012). We recognize that, even after compiling these twenty 25 ha landscapes, the study remains pseudo-replicated. Although common in elevationgradient studies, pseudo-replication yields unique interpretations that guide future studies to be replicated at multiple elevations. 


\subsection{Airborne data collection}

The airborne data were collected in August/September 2011. CAO AToMS includes a Visible-to-shortwave Infrared (VSWIR) imaging spectrometer and a dual laser, waveform lidar (Asner et al., 2012b). These sub-systems are boresight aligned onboard a Dornier 228-202 aircraft. We collected AToMS data over each study landscape from an altitude of $2000 \mathrm{~m}$ a.g.l., at an average flight speed of $55-60 \mathrm{~m} \mathrm{~s}^{-1}$ and a mapping swath of $1.2 \mathrm{~km}$.

The VSWIR spectrometer collects data in 480 contiguous spectral channels spanning the 252-2648 nm wavelength range with $5 \mathrm{~nm}$ (full-width at half-maximum) bandwidth. It has a $34^{\circ}$ field-of-view and an instantaneous field-of-view of $1 \mathrm{mrad}$. At $2000 \mathrm{~m}$ a.g.l., the VSWIR data provided $2 \mathrm{~m}$ ground sampling distance, or pixel size, throughout each study landscape. The lidar has a beam divergence set to $0.5 \mathrm{mrad}$, and was operated at $200 \mathrm{kHz}$ with $17^{\circ}$ scan halfangle from nadir, providing swath coverage similar to the VSWIR spectrometer. Because the CAO AToMS data were collected from adjacent flightlines with $50 \%$ overlap, the lidar point density achieved was approximately 2 shots $\mathrm{m}^{-2}$, or 8 shots per VSWIR pixel.

\subsection{Data processing}

Laser ranges from the lidar were combined with embedded high-resolution global positioning system-inertial measurement unit (GPS-IMU) data to determine the 3-D locations of laser returns, producing a "cloud" of lidar data. The lidar data cloud consists of a very large number of georeferenced point elevation estimates $(\mathrm{cm})$, where elevation is relative to a reference ellipsoid (WGS 1984). To estimate canopy height above ground, lidar data points were processed to identify which laser pulses penetrated the canopy volume and reached the ground surface. We used these points to interpolate a raster digital terrain model (DTM) for the ground surface. This was achieved using a $10 \mathrm{~m} \times 10 \mathrm{~m}$ kernel passed over each flight block; the lowest elevation estimate in each kernel was assumed to be ground. Subsequent points were evaluated by fitting a horizontal plane to each of the ground seed points. If the closest unclassified point was $<5.5^{\circ}$ and $<1.5 \mathrm{~m}$ higher in elevation, it was classified as ground. This process was repeated until all points within the block were evaluated. The digital surface model (DSM) was based on interpolations of all first-return points. Measurement of the vertical difference between the DTM and DSM yielded a model of canopy height above ground (digital canopy model, DCM).

The vertical distribution of lidar points was processed by binning the data into volumetric pixels (voxels) at $5 \mathrm{~m} \times 5 \mathrm{~m}$ spatial and $1 \mathrm{~m}$ vertical resolution (Asner et al., 2008). The DTM was used to standardize the vertical datum of each voxel. Therefore, the heights of each vertical "slice" of a vegetation canopy were defined relative to the ground at the horizontal center of each voxel. After all lidar points were binned in the volume cube, each vertical column of the cube was divided by the total number of lidar points in that column, yielding the percentage of lidar points that occurred in each voxel. This approach has the advantage of decreasing our sensitivity to localized variations in canopy leaf density or tree branch characteristics, which can result in a different number of lidar returns from voxel to voxel. It is important to note that our vertical profiles are based on lidar returns, which serve as proxies for actual vertical canopy profiles (Lefsky et al., 1999; Asner et al., 2008).

The VSWIR data were radiometrically corrected to radiance $\left(\mathrm{W} \mathrm{sr}^{-1} \mathrm{~m}^{-2}\right)$ using a flat-field correction, radiometric calibration coefficients, and spectral calibration data collected in the laboratory. We created a camera model to precisely describe the three-dimensional location and field-ofview of each sensor and, combined with standardized timing information, for high-precision data co-registration. A smoothed best estimate of trajectory (SBET), lidar DTM, and camera model were then used to produce an image geometry model and observational data containing information on exact solar and viewing geometry for each image pixel. These inputs were used to atmospherically correct the radiance imagery to apparent surface reflectance using the ACORN-5 model (Imspec LLC, Glendale, CA USA). To improve aerosol corrections in ACORN-5, we iteratively ran the model with different visibilities until the reflectance at $420 \mathrm{~nm}$ (which is almost constant for vegetated pixels) was $1 \%$. The reflectance data were then corrected for cross-track brightness gradients using a bidirectional reflectance distribution function (BRDF) model (Colgan et al., 2012). The imagery was then geo-orthorectified to the lidar DCM. In addition, the precise positioning of the lidar-to-VSWIR data allowed for automated masking of pixels shaded by neighboring canopies and branches, as well as water bodies (Fig. A1) (Asner et al., 2007).

\subsection{Analysis}

Descriptive statistics were generated from the lidar-derived DCM and DTM for each study landscape. In addition, topographic slope and aspect were computed using a $5 \mathrm{~m} \times 5 \mathrm{~m}$ moving kernel on the DTM. The vertical canopy profile data were averaged, plotted and compared among landscapes. From the vertical canopy profile maps, we analyzed elevation-dependent variation in understory (below upper canopy) vegetation cover in $1-3 \mathrm{~m}, 3-5 \mathrm{~m}$, and 5-10 $\mathrm{m}$ slices above ground level. We also computed a canopy shape parameter for each landscape - the ratio of the height above ground where maximum canopy volume occurs $(P)$ to the 99th percentile of total canopy height $(H)$. The $P: H$ ratio reduces a large amount of lidar vertical profile information into a simple metric depicting the overall architecture of the canopy. A high $P: H$ ratio indicates that the majority of foliage is positioned high in the canopy, independent of overall 
canopy height; a low $P: H$ ratio indicates a groundward tendency of foliar distribution.

We mapped and analyzed gaps in the forest canopy by applying a definition similar to Brokaw's (1982) definition to the DCM results whereby all gaps down to $2 \mathrm{~m}$ above ground level were mapped and their areas quantified. We also quantified the gap-size frequency distribution using the Zeta distribution, which is a discrete power-law probability density (Kellner and Asner, 2009). For the Zeta distribution with parameter $\lambda$, the probability that gap size takes the integer value $k$ is

$f(k)=\frac{k^{-\lambda}}{\xi(\lambda)}$,

where the denominator is the Riemann zeta function, and is undefined for $\lambda=1$. This distribution is sometimes called the "discrete Pareto distribution", and is appropriate for modeling the size-frequency of canopy gaps (Clauset et al., 2007; Fisher et al., 2008; White et al., 2008).

The VSWIR spectrometer images were used to generate a series of remotely sensed metrics of canopy functional traits. The results were compared at the landscape level following the application of a water and shade mask (Fig. A1), derived from the co-aligned lidar data. The normalized difference vegetation index (NDVI) was calculated as (NIR - VIS)/(NIR + VIS), where NIR and VIS were reflectances at 800 and $680 \mathrm{~nm}$, respectively. The fraction of intercepted photosynthetically active radiation (fIPAR) was mapped by subtracting the canopy reflectance in the 400 $700 \mathrm{~nm}$ PAR range, band by band from $100 \%$ reflectance, and then taking the mean of the difference among PAR spectral bands (Wessman et al., 1998).

We mapped the fractional lateral cover of photosynthetic vegetation (PV), non-photosynthetic vegetation (NPV), and bare substrate surfaces in each $2 \mathrm{~m}$ VSWIR pixel using the AutoMCU algorithm (Asner and Heidebrecht, 2002). The AutoMCU is a linear spectral mixture model that incorporates spectral endmember libraries for PV, NPV and bare substrate. Briefly, the PV spectral library was derived from airborne imaging spectrometer measurements of tropical canopy trees; NPV and bare substrate were derived from field spectrometer measurements across a wide range of tropical forest non-photosynthetic materials and soils. Critically, the PV and NPV fractional cover outputs isolate the lateral percentage cover of exposed live and dead/senescent tissues; this is not equivalent to LAI or other volume-integrating properties of canopy foliage content (Asner et al., 2005).

\section{Results}

\subsection{Terrain}

Lidar DTMs indicated 11 landscapes with mean elevations $\leq 223.3$ ma.s.l., 4 from $496.2-1712.9$ ma.s.l., and 5 from

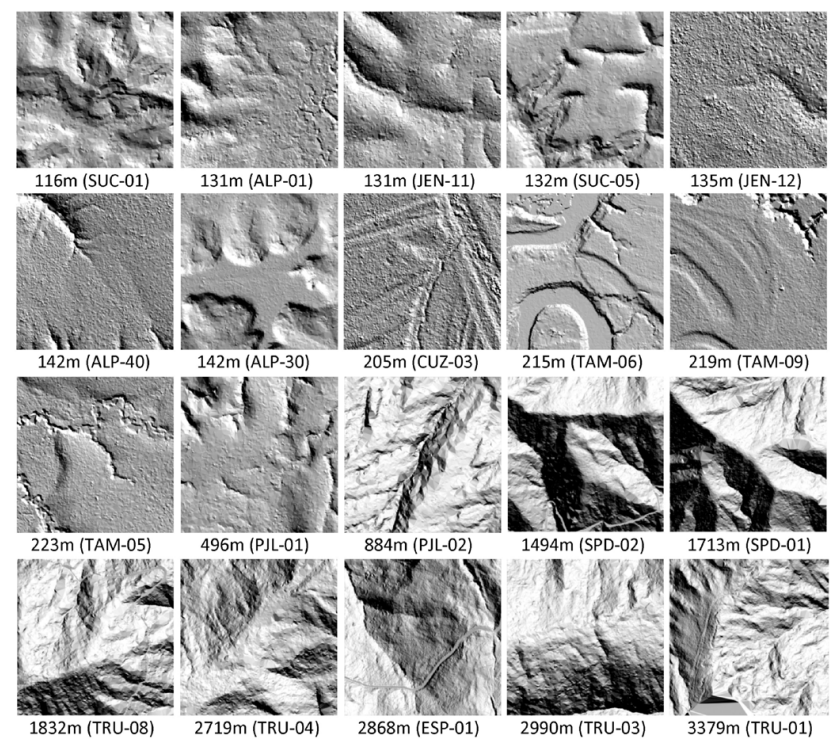

Fig. 1. Shaded relief maps showing the terrain underlying forests along an Andes-to-Amazon elevation gradient of $116 \mathrm{~m}$ to $3379 \mathrm{~m}$ a.s.l. Site names are shown in parentheses, matching those listed in Table 1 . These results are $1.1 \mathrm{~m}$ spatial resolution.

1831.5-3379.3 m a.s.1. (Table 2). Hereafter for convenience, we refer to these three groups as lowland, sub-montane and montane landscapes. Among the lowland landscapes, the variance in elevation was very low, with a maximumrecorded standard deviation (SD) of just $6.7 \mathrm{~m}$ on the ALP30 landscape (Fig. 1). Coefficients of variation (CV) in elevation averaged $1.1 \%$ among lowland landscapes. Slopes on a $5 \mathrm{~m} \times 5 \mathrm{~m}$ kernel basis ranged from a mean $( \pm \mathrm{SD})$ of $2.4^{\circ}\left(2.2^{\circ}\right)$ to $9.7^{\circ}\left(5.2^{\circ}\right)$. Throughout the lowlands, topographic aspect was oriented mostly in the north-south direction $\left(\sim 154-192^{\circ}\right.$ true $\left.\mathrm{N}\right)$.

In the sub-montane zone, we found that two landscapes - PJL-01 at $496.2 \mathrm{~m}$ and PJL-02 at $884.1 \mathrm{~m}$ - straddled a transition in topographic relief along the elevation gradient (Fig. 1). PJL-01 contained relief more similar to the other lowland landscapes, with a narrow elevation $\mathrm{SD}=5.6 \mathrm{~m}$, shallow slopes $\left(6.7^{\circ} \pm 5.6^{\circ}\right)$, and north-south-oriented aspects $\left(182.3^{\circ} \pm 111.3^{\circ}\right)$ (Table 2). In contrast, PJL-02 harbored much greater elevational variation with a $\mathrm{CV}=7 \%$ compared to $1 \%$ at PJL-01. Topographic slope increased to $31.8^{\circ} \pm 9.6^{\circ}$ at PJL-02, and aspect shifted to $143.5^{\circ} \pm 80.8^{\circ}$. This transition marked a fundamental change in terrain in terms of relief, slope and aspect that persisted into the montane landscapes. Throughout the montane forests under study, mean topographic slope ranged from 28.6-41.8 ${ }^{\circ}$. Mean aspect varied from $121.4^{\circ}$ to $189.8^{\circ}$, with the exception of ESP-01 with a mean aspect of $246.4^{\circ}$. 
Table 1. Description of 25 ha landscapes mapped and analyzed in the Andes-to-Amazon corridor. Soil orders follow the US Department of Agriculture (USDA) soil taxonomy system. Sites labeled with an asterisk $\left(^{*}\right)$ are those considered to be higher in soil fertility, as reported in the literature.

\begin{tabular}{lrrrrl}
\hline Site Name & Center latitude & Center longitude & MAP (mm) & MAT (C) & Soil order \\
\hline Sucusari; SUC-01 & -3.2519 & -72.9078 & 2754 & 26.2 & Ultisol \\
Allpahuayo; ALP-01* & -3.9491 & -73.4346 & 2760 & 26.3 & Inceptisol \\
Jenaro Herrera; JEN-11 & -4.8781 & -73.6295 & 2700 & 26.6 & Ultisol \\
Sucusari; SUC-05 & -3.2558 & -72.8942 & 2754 & 26.2 & Ultisol \\
Jenaro Herrera; JEN-12 & -4.8990 & -73.6276 & 2700 & 26.6 & Entisol \\
Allpahuayo; ALP-40 & -3.9410 & -73.4400 & 2760 & 26.3 & Entisol \\
Allpahuayo; ALP-30 & -3.9543 & -73.4267 & 2760 & 26.3 & Ultisol \\
Cuzco Amazonico; CUZ-03* & -12.5344 & -69.0539 & 2600 & 24.7 & Inceptisol \\
Tambopata; TAM-06* & -12.8385 & -69.2960 & 2600 & 24.0 & Inceptisol \\
Tambopata; TAM-09* & -12.8309 & -69.2843 & 2600 & 24.0 & Inceptisol \\
Tambopata; TAM-05 & -12.8303 & -69.2705 & 2600 & 24.0 & Ultisol \\
Paujil; PJL-01 & -10.3250 & -75.2622 & 5020 & 23.1 & Ultisol \\
Paujil; PJL-02 & -10.3300 & -75.2613 & 5020 & 23.1 & Ultisol \\
San Pedro; SPD-02* & -13.0491 & -71.5365 & 4628 & 18.5 & Inceptisol \\
San Pedro; SPD-01* & -13.0475 & -71.5423 & 4341 & 18.5 & Inceptisol \\
Mirador; TRU-08* & -13.0702 & -71.5559 & 4341 & 18.5 & Entisol \\
Trocha Union; TRU-04* & -13.1055 & -71.5893 & 2678 & 13.0 & Inceptisol \\
Esperanza; ESP-01* & -13.1751 & -71.5948 & 1705 & 12.5 & Inceptisol \\
Trocha Union; TRU-03* & -13.1097 & -71.5995 & 2678 & 13.0 & Inceptisol \\
Trocha Union; TRU-01* & -13.1136 & -71.6069 & 2448 & 8.0 & Inceptisol \\
\hline
\end{tabular}

\subsection{Canopy structure}

Along the elevation gradient, forest canopy height decreased from a mean $( \pm \mathrm{SD})$ of $24.5 \pm 7.3 \mathrm{~m}$ in the lowest lying landscape (SUC-01) to $8.9 \pm 5.6 \mathrm{~m}$ in the highest landscape (TRU-01) (Fig. 2, Table 2). Note that we masked out the river in TAM-06 in all of our vegetation analyses (Fig. A1). Elevation accounted for $72 \%$ of the regional variation in mean canopy height $(p<0.001$; RMSE $=2.75 \mathrm{~m})$. This occurred despite the fact that two lowland landscapes on dystrophic white sands (JEN-12, ALP-40) harbored vegetation with locally suppressed canopy height $(15.1-16.5 \mathrm{~m})$.

As we crossed the terrain transition from PJL-01 and PJL02 , the canopy opened up with increased prevalence of landslides at PJL-02 as well as in landscapes SPD-01 and SPD-02 further upslope (Fig. 2). Coefficients of variation in canopy height increased from an average of $33.7 \%$ for all lowland landscapes, to $43.4 \%$ for these three sites harboring increased landslide activity. At the highest elevations, the landscapes contained a sparse array of tall $(>25 \mathrm{~m})$ trees embedded in a matrix of shorter-statured (3-6 m) vegetation. This resulted in high variance of canopy height while halving of the mean canopy height (Table 2).

We measured all detectable canopy gaps reaching $2 \mathrm{~m}$ above ground level in each 25 ha landscape (Fig. 3a). The number of gaps ha ${ }^{-1}$ increased linearly with elevation $(p<0.05)$. For example, smaller gaps of $<5 \mathrm{~m}^{2}$ size were $50 \%$ more frequent in the montane than in the lowland landscapes. This was true for most other gap-size classes as well.

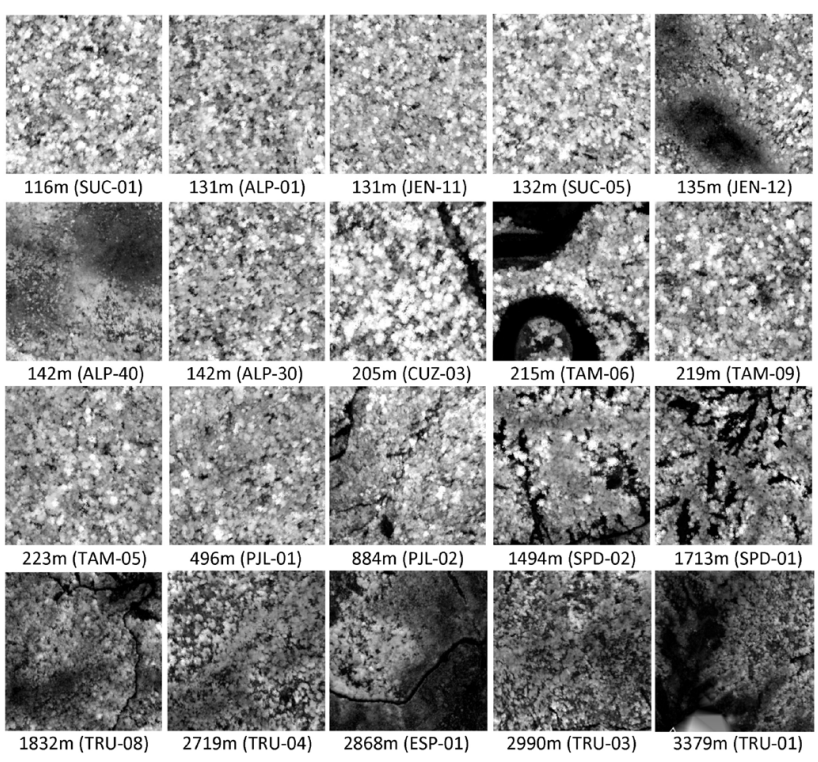

Fig. 2. Vegetation canopy height after removing variation in terrain (see Fig. 1) at $1.1 \mathrm{~m}$ spatial resolution throughout forests along the elevation gradient. Site names are shown in parentheses, matching those listed in Table 1.

Independent of elevation, gaps less than $5 \mathrm{~m}^{2}$ in size were about 10 times more common than gaps of $5-10 \mathrm{~m}^{2}$, which in turn, were about 10 times more common than gaps of 50 $200 \mathrm{~m}^{2}$. The gap-size frequency exponent $\lambda$ varied within 
Table 2. Topographic variables for 25 ha Andes-to-Amazon landscapes measured with the CAO lidar. Mean values for ground elevation, slope, aspect, and canopy height are provided with standard deviations in parentheses. The canopy shape ratio is the height of peak canopy volume $(P)$ divided by the 99th percentile total canopy height $(H)$. The canopy gap size parameter $(\lambda)$ is the negative slope of the power-law relationship between gap size and frequency.

\begin{tabular}{lrrrrrr}
\hline & & & & Canopy & Canopy & Gap Size \\
Site & $\begin{array}{r}\text { Elevation } \\
(\mathrm{m})\end{array}$ & $\begin{array}{r}\text { Slope } \\
(\mathrm{deg})\end{array}$ & $\begin{array}{r}\text { Aspect } \\
(\mathrm{deg})\end{array}$ & $\begin{array}{r}\text { Height } \\
(\mathrm{m})\end{array}$ & $\begin{array}{r}\text { Shape } \\
(P: H)\end{array}$ & $\begin{array}{r}\text { Param } \\
(\lambda)\end{array}$ \\
\hline SUC-01 & $116.6(6.2)$ & $9.7(5.2)$ & $187.9(106.8)$ & $24.5(7.3)$ & 0.558 & 1.84 \\
ALP-01 & $131.0(5.7)$ & $8.1(6.9)$ & $176.4(107.8)$ & $22.5(6.8)$ & 0.629 & 1.96 \\
JEN-11 & $131.2(2.4)$ & $9.4(7.3)$ & $192.9(102.7)$ & $23.7(6.3)$ & 0.600 & 1.93 \\
SUC-05 & $131.8(4.9)$ & $2.1(1.3)$ & $173.8(101.9)$ & $24.9(6.9)$ & 0.595 & 1.81 \\
JEN-12 & $134.9(0.6)$ & $4.6(2.9)$ & $175.3(109.8)$ & $16.5(6.5)$ & 0.417 & 2.03 \\
ALP-40 & $141.5(1.3)$ & $5.0(3.7)$ & $153.8(95.0)$ & $15.1(6.5)$ & 0.290 & 2.21 \\
ALP-30 & $142.4(6.7)$ & $2.4(2.2)$ & $179.1(102.6)$ & $21.9(7.0)$ & 0.564 & 1.84 \\
CUZ-03 & $204.9(1.2)$ & $3.0(2.2)$ & $177.7(105.0)$ & $24.0(9.9)$ & 0.609 & 1.88 \\
TAM-06 & $214.8(4.3)$ & $4.0(5.7)$ & $169.4(109.1)$ & $18.2(9.5)$ & 0.500 & 1.78 \\
TAM-09 & $219.2(1.8)$ & $4.4(4.1)$ & $192.9(100.8)$ & $21.1(7.7)$ & 0.548 & 1.80 \\
TAM-05 & $223.3(2.4)$ & $6.9(8.4)$ & $186.2(104.9)$ & $21.0(6.2)$ & 0.526 & 1.91 \\
PJL-01 & $496.2(5.6)$ & $6.7(5.6)$ & $182.3(111.3)$ & $21.2(6.1)$ & 0.568 & 1.87 \\
PJL-02 & $884.1(64.8)$ & $31.8(9.6)$ & $121.4(110.8)$ & $20.8(7.7)$ & 0.512 & 1.85 \\
SPD-02 & $1493.9(58.6)$ & $39.0(10.1)$ & $143.5(80.8)$ & $18.4(8.4)$ & 0.442 & 1.77 \\
SPD-01 & $1712.9(58.8)$ & $40.1(9.8)$ & $141.9(92.3)$ & $16.9(8.0)$ & 0.462 & 1.88 \\
TRU-08 & $1831.5(83.0)$ & $41.8(10.7)$ & $137.0(111.2)$ & $12.1(6.0)$ & 0.200 & 1.74 \\
TRU-04 & $2719.1(56.5)$ & $28.6(12.0)$ & $189.8(119.9)$ & $14.1(6.7)$ & 0.091 & 1.73 \\
ESP-01 & $2868.3(73.3)$ & $29.5(10.2)$ & $246.4(122.9)$ & $9.0(6.0)$ & 0.115 & 1.79 \\
TRU-03 & $2989.5(67.1)$ & $37.6(11.8)$ & $129.3(100.1)$ & $12.9(6.4)$ & 0.125 & 1.79 \\
TRU-01 & $3379.3(67.0)$ & $34.3(11.1)$ & $144.3(120.8)$ & $8.9(5.6)$ & 0.077 & 1.86 \\
\hline
\end{tabular}

the lowlands from about 1.75 (larger disturbances) to 2.25 (smaller disturbances) (Fig. 3b). We found a very weak linear decrease in $\lambda$ with elevation $\left(R^{2}=0.09, p<0.05\right)$.

Using the vertical canopy profile data from the lidar, we discovered systematic changes in canopy architecture with increasing elevation as well as by lowland soil type (Fig. 4). In lowland landscapes, canopies often reached heights of $40-44 \mathrm{~m}$, with the bulk of the canopy volume situated 20$25 \mathrm{~m}$ above ground level (Fig. 4a). We note that the TAM09 landscape also contained a vegetation layer about 2-3 m above ground, associated with swamp and riparian vegetation found along the Tambopata River. In contrast, the lowland landscapes on the white sands (JEN-12, ALP-40) contained canopies reaching lower maximum heights of 32-37 m, and with leaves more evenly distributed throughout the vertical profile (Fig. 4b).

The canopy $P: H$ shape ratio was inversely correlated with elevation $\left(R^{2}=0.68 ; P<0.001\right.$; RMSE $\left.=0.11\right)(\mathrm{Ta}-$ ble 2). $P$ : $H$ was $0.56 \pm 0.04$ for lowland canopies on nonsand substrates. For sands, $P: H$ declined to $0.35 \pm 0.08$, indicating a groundward shift in the vertical distribution of foliage. Canopies in the four sub-montane sites contained trees that often exceeded $40 \mathrm{~m}$ in height, but the vertical partitioning of the foliage shifted groundward in comparison to the lowland, non-sand landscapes (Fig. 4c). $P: H$ for these sites was $0.50 \pm 0.05$ (Table 2). We also found a pronounced understory layer in the 1-5 m height range. Lowstatured vegetation cover further increased in the montane landscapes, with nearly all vegetation dominating classes $<10 \mathrm{~m}$ in height (Fig. 4d). We note, however, that even the montane forests contained some trees approaching and exceeding $30 \mathrm{~m}$ in height. $P: H$ ratios for the montane landscapes were $0.12 \pm 0.05$, indicating a strong groundward shift in the vertical partitioning of the vegetation in the highest Andean Amazon forests.

We further investigated the vertical layering of the vegetation by mapping three discrete height classes or layers (1$3 \mathrm{~m}, 3-5 \mathrm{~m}$, and $5-10 \mathrm{~m}$ ) in each 25 ha landscape (Fig. 5). Note that these maps do not simply present canopy height; instead, they are maps of canopy cover within specific vertical strata, either beneath the overstory canopy or as lowstature vegetation in gaps (Asner et al., 2012b). In the lowland landscapes, these maps revealed tight spatial covariance between canopy gaps (Fig. 2) and vegetation in these short height classes. For example, the two white sand landscapes contained large patches of 1-3 m- and 3-5 m-tall vegetation (yellow colors, Fig. 5). Among the sub-montane landscapes, particularly the three with obvious signs of landslides, vegetation in the slide areas was $1-3 \mathrm{~m}$ in height (red colors, Fig. 5). Additional increases in elevation up to the montane sites resulted in large areas of each landscape dominated by lower-statured vegetation in the $1-10 \mathrm{~m}$ height classes. Field 

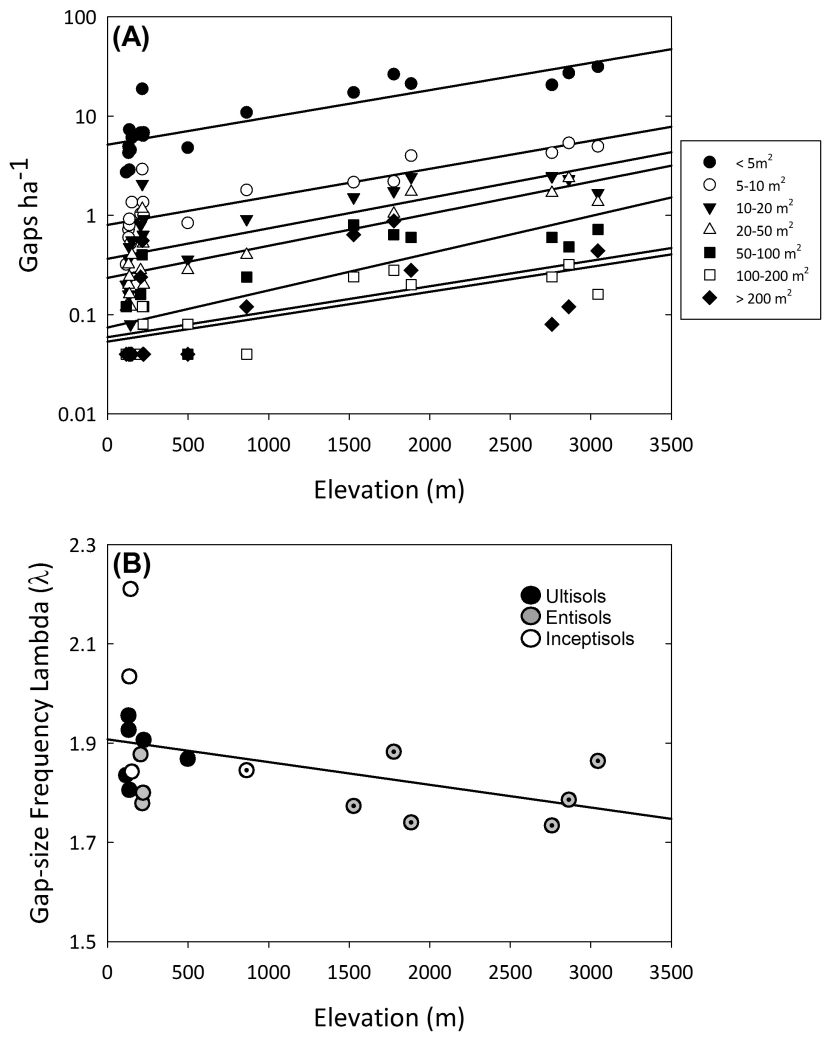

Fig. 3. (a) Changes in mean canopy gap density with increasing elevation for each 25 ha forest landscape. Gaps are computed to $2 \mathrm{~m}$ above ground level (Brokaw, 1985a) in seven gap-size classes from $<5 \mathrm{~m}^{2}$ to $>200 \mathrm{~m}^{2}$ per gap. (b) Changes in the gap-size frequency scaling coefficient $\lambda$ for each landscape along the elevation gradient. Symbols are colored by USDA soil order; and dots within circles indicate sites included in elevation-based regression of main text.

observations indicate that gap-colonizing Chusquea bamboos and ferns dominate in this low-statured montane vegetation. Regression analyses of these three vertical canopy layers revealed consistent linear increases in the percentage of understory and/or low-statured vegetation cover with elevation (Fig. 6).

We also discovered consistent relationships between the number of gaps per hectare and the percentage cover of lowstatured vegetation (Fig. 7). Specifically, we found monotonic increases in understory cover with increasing gaps $\mathrm{ha}^{-1}$, but at different rates depending upon gap size classes of $0-5 \mathrm{~m}^{2}$ to $\geq 200 \mathrm{~m}^{2}$. Steeper regression slopes were computed between understory vegetation cover and elevation in the larger gap classes. These patterns were consistent in the $1-3 \mathrm{~m}, 3-5 \mathrm{~m}$, and $5-10 \mathrm{~m}$ understory vegetation height classes. Increases in the number of gaps ha ${ }^{-1}$ in the $0-5 \mathrm{~m}^{2}$ gap-size classes resulted in the slowest increase in understory plant cover. The opposite was true for the largest $\left(\geq 200 \mathrm{~m}^{2}\right)$ gap class.
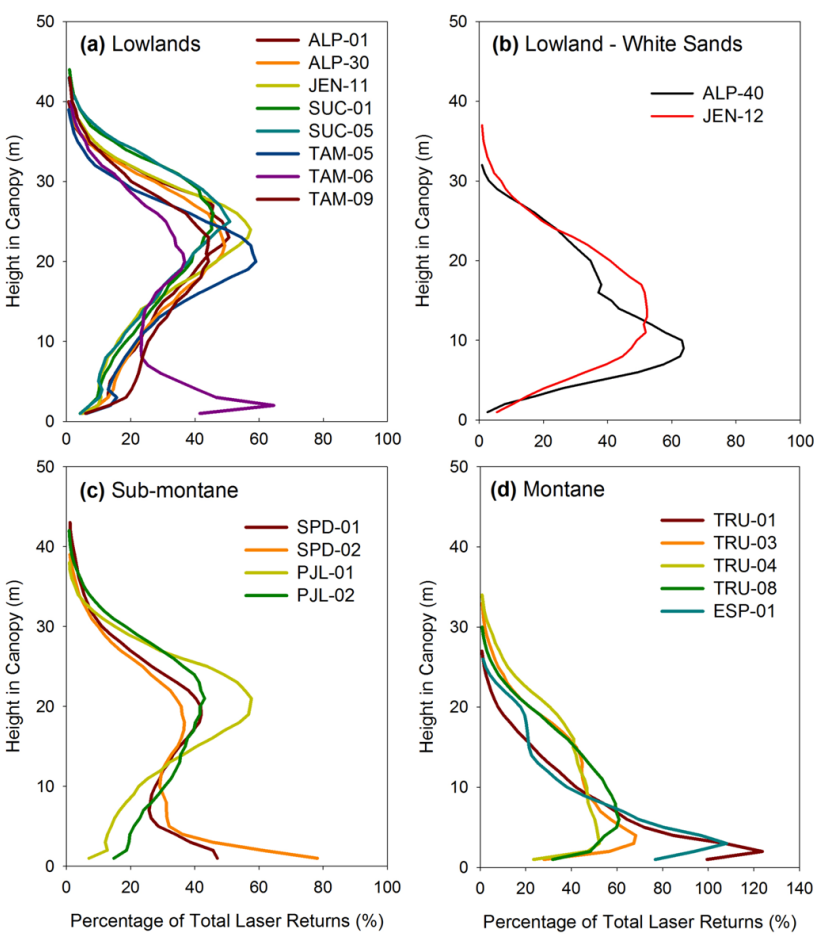

Fig. 4. Mean lidar vertical profiles for canopies in (a) lowland, (b) lowland on white sand soils, (c) sub-montane, and (d) montane forest landscapes. Site names match those provided in Table 1.
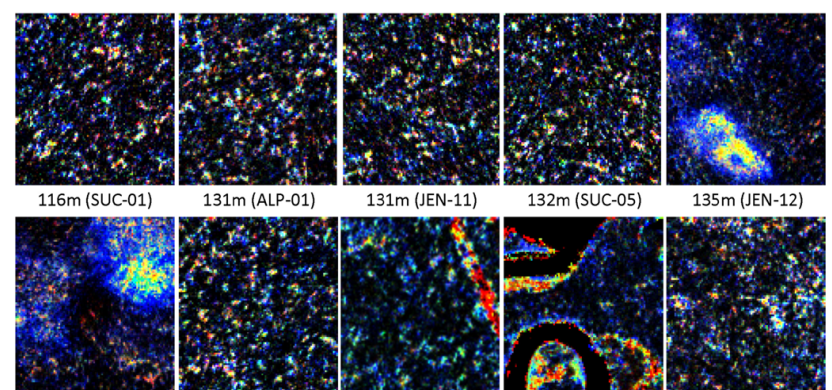

$131 \mathrm{~m}$ (JEN-11)
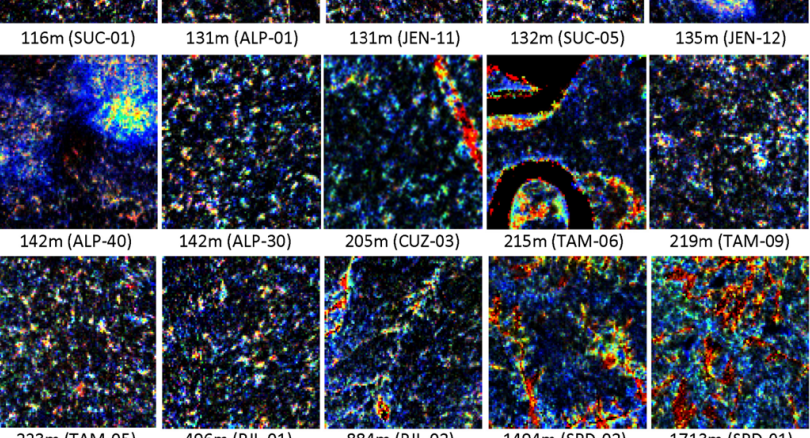

$219 \mathrm{~m}($ TAM-09)
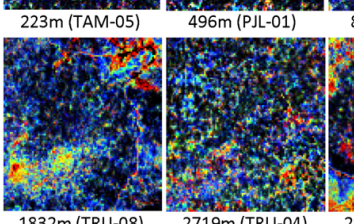

$1832 \mathrm{~m}($ TRU-08)

$2719 \mathrm{~m}($ TRU-04)

Red: $1-3 m$ Green: 3-5m Blue: 5-10m

Fig. 5. Images showing understory plant cover (presence vs. absence) in 1-3 m (red), 3-5 m (green), and 5-10 m (blue) height classes. Images are arranged by elevation to match Figs. 1 and 2 . Site names match those listed in Table 1. 

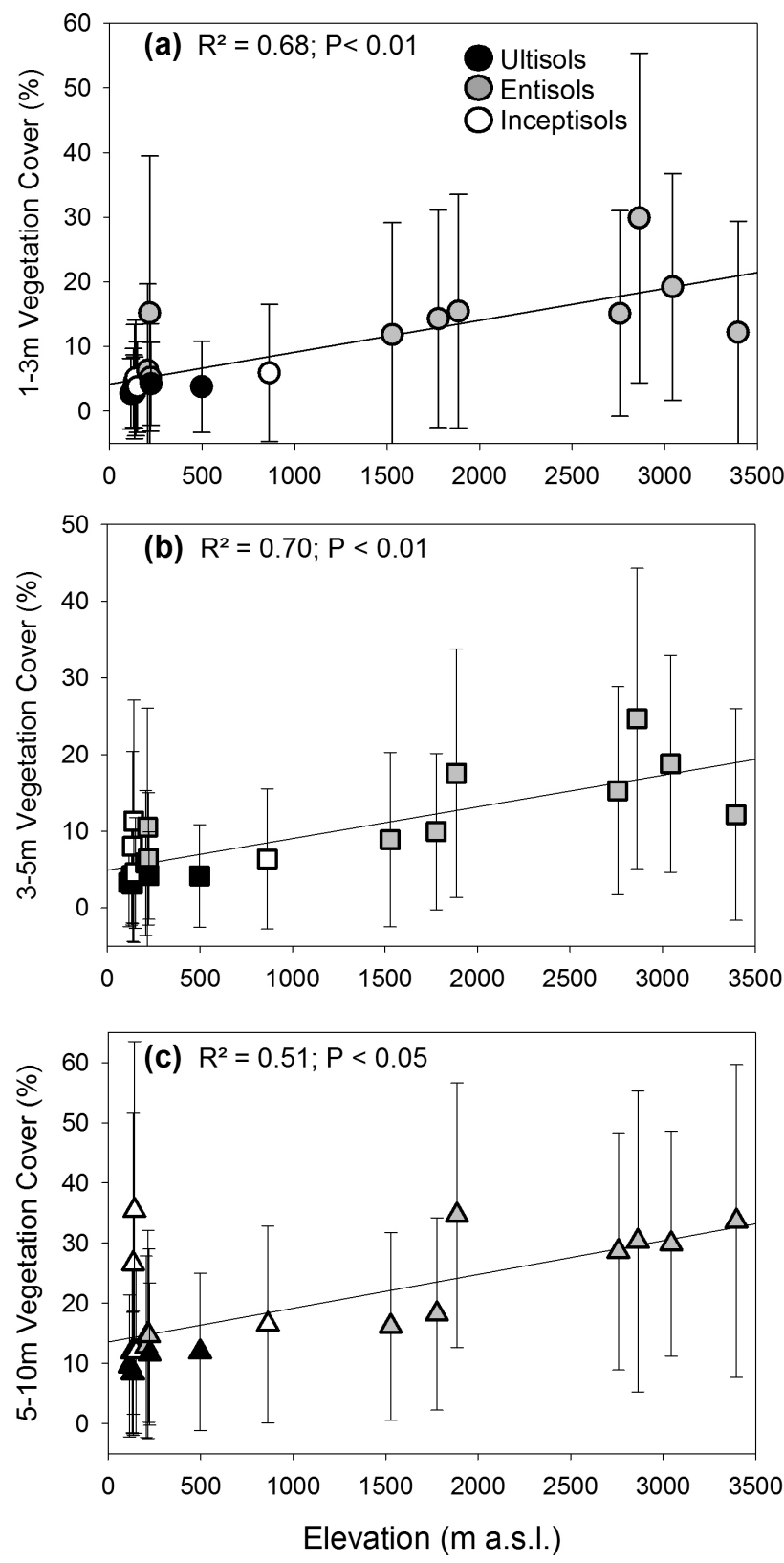

Fig. 6. Changes in mean understory canopy cover along the elevation gradient in (a) 1-3 m, (b) 3-5 m, and (c) 5-10 m height classes from Fig. 5. Error bars indicate standard deviation of canopy cover in each 25 ha forest landscape. Symbols are colored by USDA soil order.

\subsection{Canopy function}

With the VSWIR spectrometer, we mapped canopy spectral characteristics throughout each 25 ha landscape. Sites ESP01 and TRU-01 were not imaged due to poor atmospheric conditions during overflight (Fig. 8). Inspection of the colorinfrared images, each of which is histogram-matched for comparison, indicated that lowland sites contain a mix of
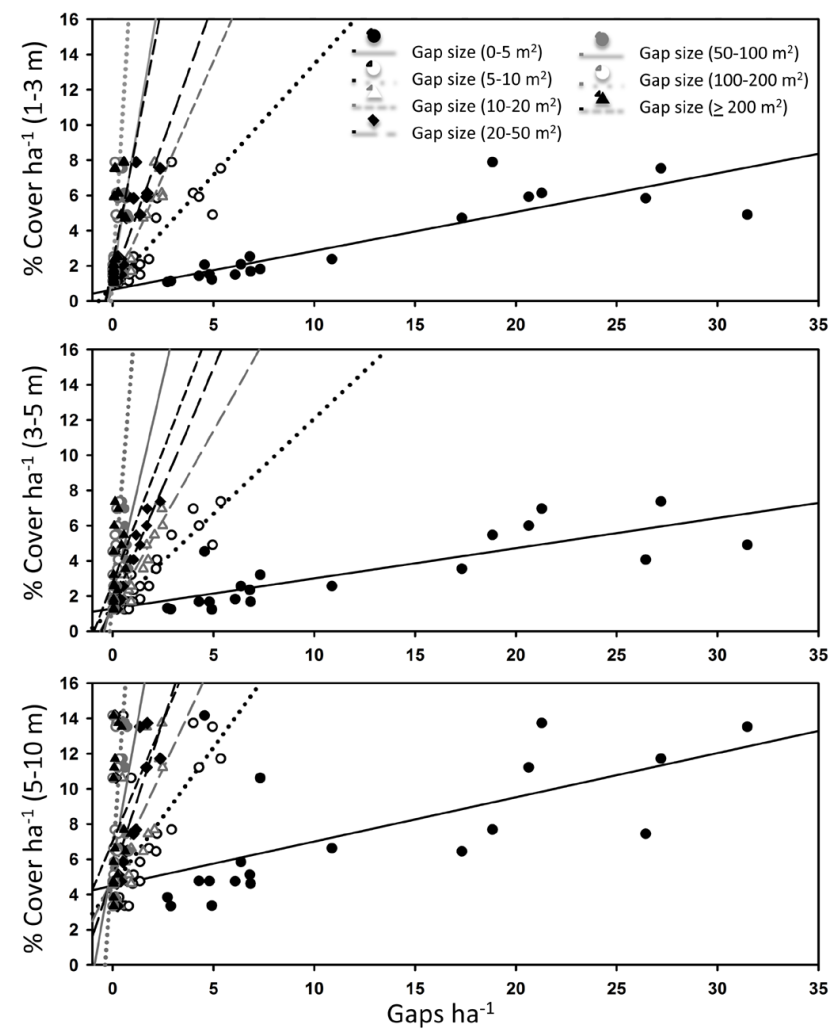

Fig. 7. Relationships between canopy gap density (see Fig. 3a) and percentage understory canopy cover (see Fig. 6) in seven gap-size classes from $<5 \mathrm{~m}^{2}$ to $>200 \mathrm{~m}^{2}$ per gap.

canopies with high near-infrared (NIR) reflectance values shown in red, and lower values in blue. The two landscapes containing the highly dystrophic white sand soils (JEN-12, ALP-40) showed larger, semi-contiguous patches of suppressed NIR reflectance. Among three of the sub-montane landscapes, the presence of landslides was also obvious as blue linearly shaped patches (Fig. 8). Otherwise, intact canopies in these sub-montane areas showed generally high NIR reflectances. The pattern changed substantially again in the montane landscapes, which showed decreases in NIR reflectance.

Plotting the VSWIR-derived canopy functional properties against elevation revealed two contrasting patterns (Fig. 9). First, among lowland landscapes, the site-level mean NDVI spanned a range of 0.87 to nearly 0.90 (Fig. 9a). Canopies on Inceptisols (floodplains) in the lowlands had a slightly suppressed average NDVI as compared to canopies on terra firme Ultisols. Second, the widely varying NDVI in the lowlands gave way to a systematic decrease in NDVI with increasing elevation among sub-montane and montane sites $\left(\operatorname{adj}-R^{2}=0.80 ; t=-4.97 ; p<0.005\right)$. This lowland versus upland (sub-montane plus montane) NDVI pattern was repeated in the measured fractional cover of photosynthetic vegetation (PV) among the landscapes (Fig. 9b). In fact, the 


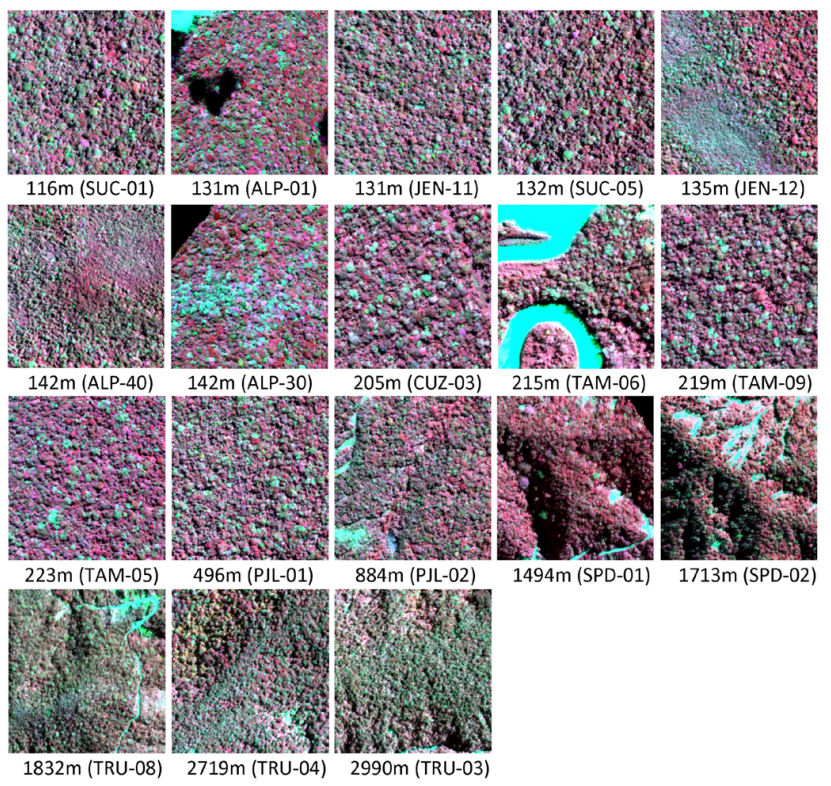

Fig. 8. Changes in narrowband, near-infrared reflectance spectroscopy of forests along the elevation gradient. Images are a combination of near-infrared $(800-809 \mathrm{~nm})$, red $(650-659 \mathrm{~nm})$, and green $(550-559 \mathrm{~nm})$ reflectance. Black areas are image edges, cloud shadows (ALP-01), and/or topographic shade (SPD-01/02).

range of $\mathrm{PV}$ in the lowlands exceeded the monotonic decrease among sub-montane to montane sites, spanning nearly $3000 \mathrm{~m}$ of elevation gain. Both the lowland and upland PV patterns were mirrored by changes in non-photosynthetic vegetation (NPV) and bare soil fractions (Fig. 9c-d). NPV increased monotonically, while bare soil decreased with elevation.

These changes in NDVI, PV, NPV and bare soil fractions occurred despite a lack of elevation trend in the fraction of photosynthetically active radiation intercepted by the vegetation (fIPAR). In fact, fIPAR remained nearly constant and highly saturated at $0.98(\mathrm{SD}=0.01)$ among sites, and there was no relationship with elevation $\left(\operatorname{adj}-R^{2}=0.17 ; p=0.10\right.$ ).

\subsection{Structure-function relationships}

We computed Pearson Product Moment correlations to assess covariances between the canopy structural and functional traits (Table 3). Any relationships described here were significant at the $p \leq 0.05$ level. The NDVI was inversely correlated with NPV and bare substrate $(S)$, and positively correlated with canopy height $(r=0.83)$ and shape $(P: H$; $r=0.86)$. NDVI was consistently negatively correlated with the number of gaps $\mathrm{ha}^{-1}$ in all gap-size classes except for the very largest gaps $(r=-0.58$ to -0.82$)$, and therefore was also negatively correlated with percentage cover of vegetation 1-10 $\mathrm{m}$ above ground level. Although canopy fIPAR was high and nearly saturated throughout the elevation gradient, it was negatively correlated with the number of canopy
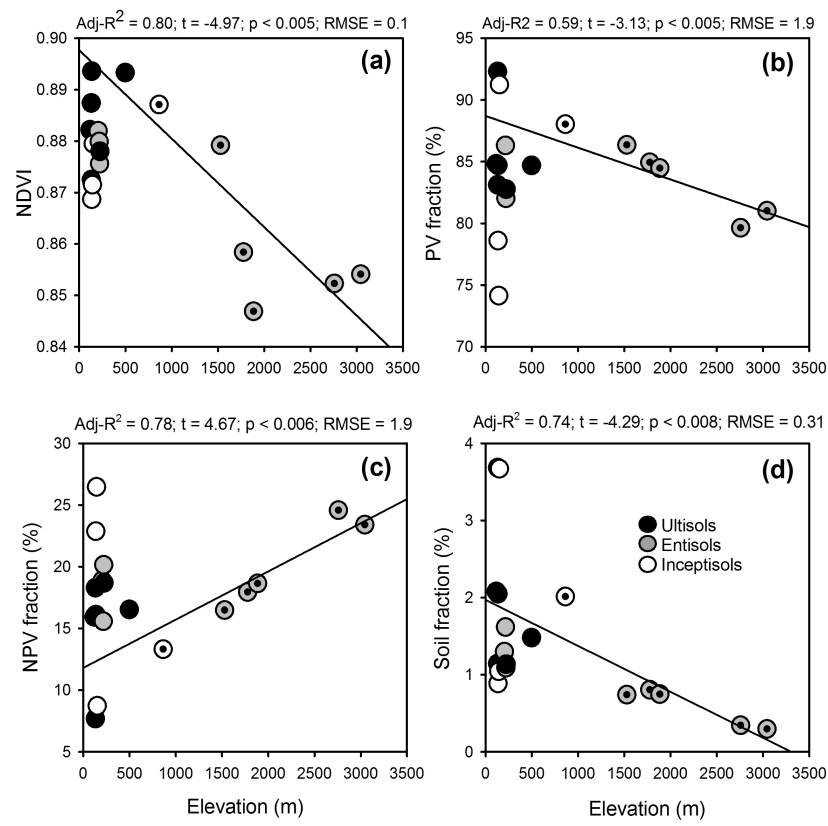

Fig. 9. Elevation-based changes in (a) NDVI, (b) PV fraction, (c) NPV fraction, and (d) soil fraction derived from imaging spectroscopy. Data are means for each 25 ha landscape. Symbols are colored by USDA soil order; and dots within circles indicate sites included in elevation-based regression of main text.

gaps $\mathrm{ha}^{-1}$ as well as vegetation cover in the $1-5 \mathrm{~m}$ height classes.

Among canopy structural properties, height was positively correlated with shape $(P: H)$ and negatively associated with gaps $\mathrm{ha}^{-1}$ and low-statured vegetation in all size and height classes, respectively (Table 3 ). The gap-size frequency parameter $\lambda$ was also negatively correlated with gaps $\mathrm{ha}^{-1}$ and vegetation in the $1-3 \mathrm{~m}$ height class. Finally, many of the gap-size classes were inter-correlated, while canopy height was not related to the gap size-frequency $\lambda$.

\section{Discussion}

Very few regions of the world offer $3200 \mathrm{~m}$ of elevation change while maintaining humid tropical forest conditions. The gradient considered in this study provided this rare setting to assess the role of elevational change in determining vegetation structure, functional traits, and their interactions. Although elevation was the primary independent factor of interest here, we also found a relationship between elevation and slope $(r=0.78 ; p<0.05)$. Moreover, we found that the terrain hidden beneath the forest canopy changed in non-linear ways: (i) landscapes below $500 \mathrm{~m}$ a.s.l. harbored mostly flat terrain; (ii) a transition occurred between $500 \mathrm{~m}$ and $880 \mathrm{~m}$ elevation from lowland to montane terrain conditions; and (iii) landscapes above $880 \mathrm{~m}$ to treeline bore steep terrain (Fig. 1). Higher elevations are usually associated with 
Table 3. Inter-relationships among landscape-scale canopy functional and structural traits along the elevation gradient. Values are Pearson Product Moment correlation coefficients $(r)$ with bold font indicating $p$ values $\leq 0.05$.

\begin{tabular}{|c|c|c|c|c|c|c|c|c|c|c|c|c|c|c|c|c|c|c|}
\hline & \multirow[b]{2}{*}{ NDVI } & \multirow[b]{2}{*}{ PV } & \multirow[b]{2}{*}{ NPV } & \multirow[b]{2}{*}{$S$} & \multirow[b]{2}{*}{ fIPAR } & \multirow[b]{2}{*}{ Height } & \multirow[b]{2}{*}{$P: H$} & \multirow[b]{2}{*}{ Gap-size $\lambda$} & \multicolumn{7}{|c|}{ Number of gaps in a size class $\left(\mathrm{m}^{2}\right)$ per ha } & \multicolumn{3}{|c|}{$\begin{array}{c}\% \text { cover in } \\
\text { height class (m) }\end{array}$} \\
\hline & & & & & & & & & $\leq 5$ & $5-10$ & $10-20$ & $20-50$ & 50-100 & $100-200$ & $\geq 200$ & $1-3$ & $3-5$ & $5-10$ \\
\hline NDVI & - & 0.42 & -0.58 & -0.63 & 0.66 & 0.83 & 0.86 & 0.18 & -0.77 & -0.79 & -0.74 & -0.82 & -0.58 & -0.73 & -0.21 & -0.68 & -0.82 & -0.70 \\
\hline PV & & - & -0.97 & 0.75 & 0.21 & 0.45 & 0.53 & -0.42 & -0.06 & -0.10 & -0.06 & -0.09 & 0.04 & -0.10 & 0.17 & -0.13 & -0.38 & -0.62 \\
\hline NPV & & & - & -0.87 & 0.10 & -0.58 & -0.66 & 0.23 & 0.28 & 0.31 & 0.28 & 0.31 & 0.17 & 0.32 & -0.05 & 0.31 & 0.53 & 0.67 \\
\hline$S$ & & & & - & 0.04 & 0.61 & 0.63 & 0.11 & -0.55 & -0.49 & -0.55 & -0.48 & -0.52 & -0.61 & -0.29 & -0.52 & -0.59 & -0.57 \\
\hline fIPAR & & & & & - & 0.35 & 0.38 & 0.16 & -0.64 & -0.50 & -0.55 & -0.54 & -0.50 & -0.47 & -0.47 & -0.55 & -0.55 & -0.48 \\
\hline Height & & & & & & - & 0.94 & 0.04 & -0.82 & -0.82 & -0.71 & -0.75 & -0.68 & -0.63 & -0.35 & -0.71 & -0.87 & -0.94 \\
\hline$P: H$ & & & & & & & - & 0.13 & -0.76 & -0.85 & -0.71 & -0.79 & -0.65 & -0.65 & -0.17 & -0.66 & -0.86 & -0.90 \\
\hline Gap-size $\lambda$ & & & & & & & & - & -0.41 & -0.52 & -0.60 & -0.55 & -0.53 & -0.53 & -0.26 & -0.48 & -0.25 & 0.16 \\
\hline $\mathrm{Gap} \leq 5 \mathrm{~m}^{2}$ & & & & & & & & & - & 0.92 & 0.89 & 0.87 & 0.90 & 0.87 & 0.68 & 0.89 & 0.81 & 0.63 \\
\hline Gap 5-10 $\mathrm{m}^{2}$ & & & & & & & & & & - & 0.90 & 0.96 & 0.80 & 0.80 & 0.37 & 0.86 & 0.87 & 0.67 \\
\hline Gap $10-20 \mathrm{~m}^{2}$ & & & & & & & & & & & - & 0.92 & 0.86 & 0.86 & 0.55 & 0.94 & 0.86 & 0.56 \\
\hline Gap $20-50 \mathrm{~m}^{2}$ & & & & & & & & & & & & - & 0.75 & 0.86 & 0.37 & 0.90 & 0.90 & 0.62 \\
\hline Gap $50-100 \mathrm{~m}^{2}$ & & & & & & & & & & & & & - & 0.87 & 0.76 & 0.82 & 0.69 & 0.48 \\
\hline Gap $100-200 \mathrm{~m}^{2}$ & & & & & & & & & & & & & & - & 0.62 & 0.85 & 0.75 & 0.46 \\
\hline Gap $\geq 200 \mathrm{~m}^{2}$ & & & & & & & & & & & & & & & - & 0.64 & 0.38 & 0.18 \\
\hline $1-3 \mathrm{~m}$ cover & & & & & & & & & & & & & & & & - & 0.90 & 0.58 \\
\hline $3-5 \mathrm{~m}$ cover & & & & & & & & & & & & & & & & & - & 0.85 \\
\hline $5-10 \mathrm{~m}$ cover & & & & & & & & & & & & & & & & & & - \\
\hline
\end{tabular}

steeper slopes in tectonically active areas, consistent with coarser resolution data for the region (e.g., Regard et al., 2009).

These threshold changes in topography were, to some extent, expressed in non-systematic changes in canopy functional traits. For example, we found very wide-ranging values of NDVI, PV, NPV and bare substrate in our 25 ha study landscapes across the lowlands. Wide-ranging lowland variability then gave way to monotonic, and often less extensive, changes in these functional metrics above $400 \mathrm{~m}$ elevation (Fig. 9). Since NDVI, PV and NPV are known correlates with canopy greenness, leaf cover, and exposed nonphotosynthetic vegetation, respectively (Roberts et al., 1997; Asner et al., 2005; Gamon et al., 1995), our findings highlight the strong degree to which canopy structural and functional variation is linked to regional patterns of geologic, hydrologic, and soil fertility variation in the lowlands. This finding may also reflect reports of widely varying community composition, productivity, and carbon storage throughout the western Amazonian lowlands (Quesada et al., 2012; Asner et al., 2012a; Higgins et al., 2012; Aragão et al., 2009; Girardin et al., 2014; Carvalho et al., 2013; Tuomisto et al., 1995).

In contrast to the wide-ranging functional trait variation observed in the lowlands, variability in canopy structural properties was mostly tied to changes in elevation alone. For example, the number of gaps ha ${ }^{-1}$ (Fig. 3) and the percentage cover of understory vegetation (Fig. 6) were consistent in the lowlands and then linearly increased to treeline. Canopy height and the canopy $P: H$ ratio also declined linearly with elevation (Table 2). Moreover, we discovered systematic changes in the vertical distribution of plant tissues in lowland to sub-montane, and to montane forest environments (Fig. 4). Exceptions to these rules were found in the two highly dystrophic, white sand landscapes in northern Peru (JEN-12, ALP-40), which harbored locally suppressed canopy height and a groundward shift in canopy vertical profiles. So while elevation is the regionally dominant control on canopy structural characteristics, soil fertility also plays a role in creating structural diversity among a subset of lowland forest types (Fig. 10).

Although we discovered a number of elevation-dependent trends in canopy characteristics, we also found coordinated variation among many of the properties. For example, canopy height and shape were highly correlated, and both of these properties were negatively related to gap density (Table 3). Moreover, gap densities increased with elevation (Fig. 3), while canopy height decreased with elevation (Table 2). In Peruvian forests, canopy height $(\mathrm{CH})$ is highly correlated with aboveground biomass at the stand level $\left(0.4356 \cdot \mathrm{CH}^{1.7551} ; R^{2}=0.89 ; p<0.001\right)$, whereas standlevel wood density is not $\left(R^{2}=0.08 ; p=0.16\right.$ ) (Asner et al., 2012c). Therefore, canopy height is a good surrogate for aboveground biomass along our elevation gradient. In Peru, 1 ha field plot studies indicated that aboveground biomass decreases from about $88-138 \mathrm{Mg} \mathrm{Cha}^{-1}$ in the lowlands, depending upon soil type, to about $47-66 \mathrm{Mg} \mathrm{C} \mathrm{ha}^{-1}$ near treeline, or up to $66 \%$ overall (Girardin et al., 2014; Huaraca Huasco et al., 2014). After we convert lidar-based estimates of canopy height to aboveground biomass estimates using the Peru equations provided by Asner and Mascaro (2014), we obtain an elevation-dependent trend in aboveground biomass stocks that is within $10 \%$ of the plot-based estimates. Thus our estimated decreases in aboveground biomass at the 25 ha scale corroborate 1 ha plot estimates of biomass decreases with increasing elevation.

Field studies also suggest that NPP decreases with increasing elevation in the Andes-to-Amazon corridor (Girardin et al., 2010; Moser et al., 2011), and this may be reflected in the observed NDVI decreases at higher elevations (Fig. 9a). Traditionally, the NDVI has been linked to light absorption, 


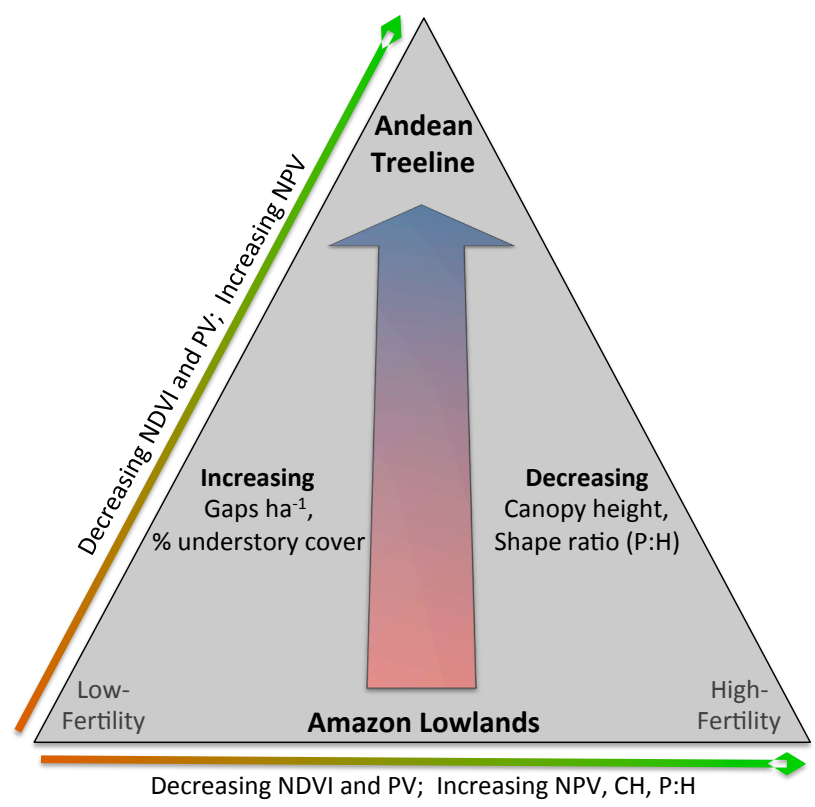

Fig. 10. Summary of results presented in the study: as elevation increases from the Amazon lowlands to Andean treeline, the forest canopy undergoes increases in canopy gap density and understory plant cover, while canopy height and shape ratio $(P: H)$ decrease. Functional trait metrics of NDVI and fractional PV cover decrease, while fractional NPV cover increases, from low-fertility sites in the lowlands to Andean treeline. A similar trend occurs from low- to high-fertility lowland sites. Additionally, canopy height and the shape ratio increase from low- to high-fertility sites within the lowlands.

among other canopy factors (Hatfield, 1984; Goward and Huemmrich, 1992; Sellers et al., 1995; Myneni et al., 1997). However, we found that fractional intercepted PAR, or fIPAR, was saturated and nearly constant among the twenty 25 ha landscapes throughout our gradient, so it is unlikely that the NDVI is simply tracking photosynthetically active light absorption. Instead, we found that, as elevation increases, the NDVI decreases while gap density increases (Table 3). We thus hypothesize that the NDVI is suppressed at higher elevations due to slower gap closure rates associated with suppressed NPP.

Although aboveground biomass and NDVI decrease with increasing elevation, we computed a near-constant gapsize scaling parameter $\lambda$ throughout the elevation gradient (Fig. 3). $\lambda$ is a quantitative index often used to compare and contrast biomass turnover rates in tropical forests (Gloor et al., 2009; Asner et al., 2013; Chambers et al., 2013). Our results thus suggest that turnover rates are relatively constant when ascending from the lowlands into the montane. Not only would this corroborate previous plot-based studies of nearly constant turnover (Girardin et al., 2010), they point out the potential value of airborne remote sensing for gapsize frequency mapping in large forested regions of Amazonia. Doing so will improve our understanding of the spatial distribution of growth and mortality at much broader ecological scales than can be achieved with field plots.

Our results provide insight into the relationship between gap formation patterns and understory plant cover. Understory cover increases with elevation (Fig. 10). This trend is driven by increases in gap density, but at differential rates depending upon gap size and vegetation height (Fig. 7). It takes about 25-30 times the number of $0-5 \mathrm{~m}^{2}$ gaps to produce understory responses created in a single $20-200 \mathrm{~m}^{2}$ gap. These results suggest a strong limiting role of low light availability on understory plant cover in forests spanning the lowland Amazon to the Andean treeline. Although this issue is already well appreciated in the tropical forest literature (Denslow, 1987; Lawton, 1990), quantification of light response thresholds have remained elusive due to the impracticalities of field measurements in highly heterogeneous understory light environments (Chazdon, 1988). Here we show that, for western Amazonian forests, gaps larger than $5 \mathrm{~m}^{2}$ are associated with the largest understory plant cover values. Independent of gap size or density, the percentage cover of understory plants never exceeds $8 \%$ per hectare for $1-3 \mathrm{~m}$ or 3-5 m-tall plants, while it often reaches but does not exceed $14 \%$ per hectare for plants of 5-10 $\mathrm{m}$ in height. These estimates provide the first constraints on models of disturbance, demography and ecosystem processes in Amazonian forests of widely varying structure and composition.

The Andes-to-Amazon corridor remains virtually unexplored scientifically. With thousands of valleys, diverse terrain conditions, and variable soils, there exists a vast frontier still to be unravelled. Tropical elevation studies have traditionally relied upon field plots that are distributed in sparse patterns on highly variable terrain. Although plot-based studies are key to understanding ecological processes such as productivity and biogeochemical fluxes, field measurements of canopy structural and functional traits are extremely hard to obtain, resulting in limited methods to extend plot-based measurements to larger ecological scales. Using new airborne remote measurement techniques, we reported a first analysis of landscape-scale canopy functional and structural traits along an Andes-to-Amazon elevation gradient. Integrated hyperspectral and lidar measurements allowed us to draw conclusions on the way elevation, terrain and soils affect the three-dimensional forest habitat and its dynamics. Our results are a step toward unravelling structural and functional composition in one of the most biologically diverse regions of our planet.

Acknowledgements. We thank T. Kennedy-Bowdoin and other team members for assistance with data processing. This study was supported by the John D. and Catherine T. MacArthur Foundation and the endowment of the Carnegie Institution for Science. The Carnegie Airborne Observatory is made possible by the Avatar Alliance Foundation, Grantham Foundation for the Protection of the Environment, John D. and Catherine T. MacArthur Foundation, 


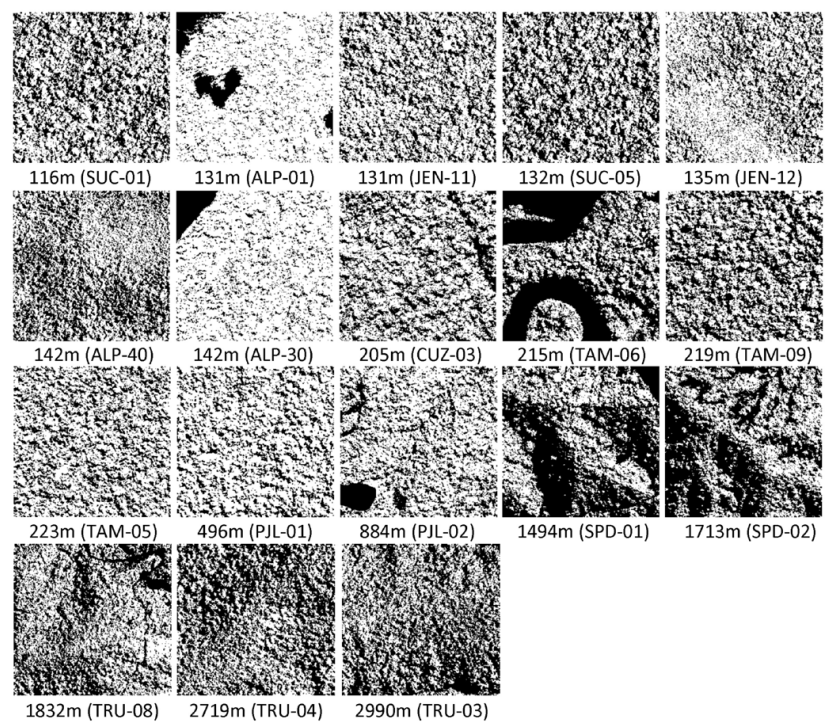

Fig. A1. Shade, ground and water mask (black areas) developed from airborne lidar and applied to all imaging spectrometer analyses (see Fig. 8).

Gordon and Betty Moore Foundation, W. M. Keck Foundation, Margaret A. Cargill Foundation, Mary Anne Nyburg Baker and G. Leonard Baker Jr., and William R. Hearst III.

Edited by: K. Thonicke

\section{References}

Alves, L. F., Vieira, S. A., Scaranello, M. A., Camargo, P. B., Santos, F. A. M., Joly, C. A., and Martinelli, L. A.: Forest structure and live aboveground biomass variation along an elevational gradient of tropical Atlantic moist forest (Brazil), Forest Ecol. Manage., 260, 679-691, doi:10.1016/j.foreco.2010.05.023, 2010.

Aragão, L. E. O. C., Malhi, Y., Metcalfe, D. B., Silva-Espejo, J. E., Jiménez, E., Navarrete, D., Almeida, S., Costa, A. C. L., Salinas, N., Phillips, O. L., Anderson, L. O., Alvarez, E., Baker, T. R., Goncalvez, P. H., Huamán-Ovalle, J., Mamani-Solórzano, M., Meir, P., Monteagudo, A., Patiño, S., Peñuela, M. C., Prieto, A., Quesada, C. A., Rozas-Dávila, A., Rudas, A., Silva Jr., J. A., and Vásquez, R.: Above- and below-ground net primary productivity across ten Amazonian forests on contrasting soils, Biogeosciences, 6, 2759-2778, doi:10.5194/bg-6-2759-2009, 2009.

Asner, G. P. and Heidebrecht, K. B.: Spectral unmixing of vegetation, soil and dry carbon cover in arid regions: comparing multispectral and hyperspectral observations, Int. J. Remote Sens., 23, 3939-3958, 2002.

Asner, G. P. and Mascaro, J.: Mapping tropical forest carbon: Calibrating plot estimates to a simple LiDAR metric, Remote Sens. Environ., 140, 614-624, 2014.

Asner, G. P., Wessman, C. A., and Archer, S.: Scale dependence of absorption of photosynthetically active radiation in terrestrial ecosystems, Ecol. Appl., 8, 1003-1021, 1998.
Asner, G. P., Elmore, A. J., Hughes, F. R., Warner, A. S., and Vitousek , P. M.: Ecosystem structure along bioclimatic gradients in Hawai'i from imaging spectroscopy, Remote Sens. Environ., 96, 497-508, 2005.

Asner, G. P., Knapp, D. E., Kennedy-Bowdoin, T., Jones, M. O., Martin, R. E., Boardman, J., and Field, C. B.: Carnegie Airborne Observatory: In-flight fusion of hyperspectral imaging and waveform light detection and ranging (LiDAR) for threedimensional studies of ecosystems, J. Appl. Remote Sens., 1, 013536, doi:10.1117/1111.2794018, 2007.

Asner, G. P., Hughes, R. F., Vitousek, P. M., Knapp, D. E., KennedyBowdoin, T., Boardman, J., Martin, R. E., Eastwood, M., and Green, R. O.: Invasive plants transform the 3-D structure of rainforests, P. Natl. Acad. Sci., 105, 4519-4523, 2008.

Asner, G. P., Powell, G. V. N., Mascaro, J., Knapp, D. E., Clark, J. K., Jacobson, J., Kennedy-Bowdoin, T., Balaji, A., Paez-Acosta, G., Victoria, E., Secada, L., Valqui, M., and Hughes, R. F.: Highresolution forest carbon stocks and emissions in the Amazon, P. Natl. Acad. Sci., 107, 16738-16742, 2010.

Asner, G. P., Clark, J. K., Mascaro, J., Galindo García, G. A., Chadwick, K. D., Navarrete Encinales, D. A., Paez-Acosta, G., Cabrera Montenegro, E., Kennedy-Bowdoin, T., Duque, Á., Balaji, A., von Hildebrand, P., Maatoug, L., Phillips Bernal, J. F., Yepes Quintero, A. P., Knapp, D. E., García Dávila, M. C., Jacobson, J., and Ordóñez, M. F.: High-resolution mapping of forest carbon stocks in the Colombian Amazon, Biogeosciences, 9, 26832696, doi:10.5194/bg-9-2683-2012, 2012a.

Asner, G. P., Knapp, D. E., Boardman, J., Green, R. O., Kennedy-Bowdoin, T., Eastwood, M., Martin, R. E., Anderson, C., and Field, C. B.: Carnegie Airborne Observatory2: Increasing science data dimensionality via high-fidelity multi-sensor fusion, Remote Sens. Environ., 124, 454-465, doi:10.1016/j.rse.2012.06.012, 2012 b.

Asner, G. P., Mascaro, J., Muller-Landau, H. C., Vieilledent, G., Vaudry, R., Rasamoelina, M., Hall, J. S., and van Breugel, M.: A universal airborne LiDAR approach for tropical forest carbon mapping, Oecologia, 168, 1147-1160, doi:10.1007/s00442-0112165-z, 2012c.

Asner, G. P., Kellner, J. R., Kennedy-Bowdoin, T., Knapp, D. E., Anderson, C., and Martin, R. E.: Forest canopy gap distributions in the southern Peruvian Amazon, PLoS ONE, 8, e60875, doi:10.1371/journal.pone.0060875, 2013.

Baker, T. R., Phillips, O. L., Malhi, Y., Almeida, S. A. S., Arroyo, L., Di Fiore, A., Erwin, T., Killeen, T. J., Laurance, S. G., Laurance, W. F., Lewis, S. L., Lloyd, J., Manteagudo, A., Neill, D. A., Patino, S., Pitman, N. C. A., Natalino, J., Silva, M., and Martinez, R. V.: Variation in wood density determines spatial patterns in Amazonia forest biomass, Glob. Change Biol., 10, 545-562, 2004.

Brokaw, N. V.: The definition of treefall gap and its effect on measures of forest dynamics, Biotropica, 14, 158-160, 1982.

Brokaw, N. V.: Gap-phase regeneration in a tropical forest, Ecology, 66, 682-687, 1985a.

Brokaw, N. V. L.: Treefalls, regrowth, and community structure in tropical forests, in: The ecology of natural disturbance and patch dynamics, edited by: Pickett, S. T. A. and White, P. S., Academic Press, New York, 53-69, 1985b.

Carvalho, A. L. D., Nelson, B. W., Bianchini, M. C., Plagnol, D., Kuplich, T. M., and Daly, D. C.: Bamboo-Dominated Forests 
of the Southwest Amazon: Detection, Spatial Extent, Life Cycle Length and Flowering Waves, PLoS ONE, 8, e54852, doi:10.1371/journal.pone.0054852, 2013.

Chambers, J. Q., Negron-Juarez, R. I., Marra, D. M., Di Vittorio, A., Tews, J., Roberts, D., Ribeiro, G. H. P. M., Trumbore, S. E., and Higuchi, N.: The steady-state mosaic of disturbance and succession across an old-growth Central Amazon forest landscape, P. Natl. Acad. Sci., 110, 3949-3954, 2013.

Chazdon, R. L.: Sunflecks and their importance to forest understorey plants, Adv. Ecol. Res., 18, 1-63, 1988.

Clauset, A., Shalizi, C. R., and Newman, M. E. J.: Power-law distributions in empirical data, SIAM Review, 51, 661-703, 2007.

Colgan, M., Baldeck, C., Féret, J.-B., and Asner, G.: Mapping Savanna Tree Species at Ecosystem Scales Using Support Vector Machine Classification and BRDF Correction on Airborne Hyperspectral and LiDAR Data, Remote Sensing, 4, 3462-3480, 2012.

Denslow, J. S.: Tropical rainforest gaps and tree species diversity, Annu. Rev. Ecol. Syst., 18, 431-451, 1987.

Drake, J. B., Dubayah, R. O., Clark, D. B., Knox, R. G., Blair, J. B., Hofton, M. A., Chazdon, R. L., Weishampel, J. F., and Prince, S. D.: Estimation of tropical forest structural characteristics using large-footprint lidar, Remote Sens. Environ., 79, 305-319, 2002.

Fine, P. V. A., Mesones, I., and Coley, P. D.: Herbivores promote habitat specialization by trees in Amazonian forests, Science, 305, 663-665, doi:10.1126/science.1098982, 2004.

Fisher, J. I., Hurtt, G. C., Thomas, R. Q., and Chambers, J. Q.: Clustered disturbances lead to bias in large-scale estimates based on forest sample plots, Ecol. Lett., 11, 554-563, 2008.

Fyllas, N. M., Patiño, S., Baker, T. R., Bielefeld Nardoto, G., Martinelli, L. A., Quesada, C. A., Paiva, R., Schwarz, M., Horna, V., Mercado, L. M., Santos, A., Arroyo, L., Jiménez, E. M., Luizão, F. J., Neill, D. A., Silva, N., Prieto, A., Rudas, A., Silviera, M., Vieira, I. C. G., Lopez-Gonzalez, G., Malhi, Y., Phillips, O. L., and Lloyd, J.: Basin-wide variations in foliar properties of Amazonian forest: phylogeny, soils and climate, Biogeosciences, 6 , 2677-2708, doi:10.5194/bg-6-2677-2009, 2009.

Gamon, J. A., Field, C. B., Goulden, M. L., Griffin, K. L., Hartley, A. E., Joel, G., Peñuelas, J., and Valentini, R.: Relationships between NDVI, canopy structure, and photosynthesis in three Californian vegetation types, Ecol. Appl., 5, 28-41, 1995.

Gentry, A. H.: Changes in Plant Community Diversity and Floristic Composition on Environmental and Geographical Gradients, Ann. Mo. Bot. Gard., 75, 1-34, 1988.

Girardin, C. A. J., Malhi, Y., Aragão, L. E. O. C., Mamani, M., Huaraca Huasco, W., Durand, L., Feeley, K. J., Rapp, J., Silva-Espejo, J. E., Silman, M., Salinas, N., and Whittaker, R. J.: Net primary productivity allocation and cycling of carbon along a tropical forest elevational transect in the Peruvian Andes, Glob. Change Biol., 16, 3176-3192, doi:10.1111/j.13652486.2010.02235.x, 2010.

Girardin, C. A. J., Farfan-Rios, W., Garcia, K., Feeley, K. J., Jorgensen, P. M., Murakami, A. A., Pérez, L. C., Seide, R., Paniagua, N., Claros, A. F., Maldonado, C., Silman, M., Salinas, N., Reynel, C., Neill, D. A., Serrano, M., Caballero, C. J., Cuadros, M. A. T., Macía, M. J., Killeen, T. J., and Malhi, Y.: Comparison of biomass and structure in various elevation gradients in the Andes, Plant Ecol. Div., 6, 100-110, 2014.
Gloor, M., Phillips, O. L., Lloyd, J. J., Lewis, S. L., Malhi, Y., Baker, T. R., Lopez-Gonzalez, G., Peacock, J., Almeida, S., de Oliveira, A. C. A., Alvarez, E., Amaral, I., Arroyo, L., Aymard, G., Banki, O., Blanc, L., Bonal, D., Brando, P., Chao, K. J., Chave, J., Davila, N., Erwin, T., Silva, J., Di Fiore, A., Feldpausch, T. R., Freitas, A., Herrera, R., Higuchi, N., Honorio, E., Jimenez, E., Killeen, T., Laurance, W., Mendoza, C., Monteagudo, A., Andrade, A., Neill, D., Nepstad, D., Vargas, P. N., Penuela, M. C., Cruz, A. P., Prieto, A., Pitman, N., Quesada, C., Salomao, R., Silveira, M., Schwarz, M., Stropp, J., Ramirez, F., Ramirez, H., Rudas, A., ter Steege, H., Silva, N., Torres, A., Terborgh, J., Vasquez, R., and van der Heijden, G.: Does the disturbance hypothesis explain the biomass increase in basin-wide Amazon forest plot data?, Glob. Change Biol., 15, 2418-2430, doi:10.1111/j.1365-2486.2009.01891.x, 2009.

Goward, S. N. and Huemmrich, K. F.: Vegetation canopy PAR absorptance and the normalized difference vegetation index: an assessment using the SAIL model, Remote Sens. Environ., 39, 119-140, 1992.

Hatfield, J. L.: Intercepted photosynthetically active radiation estimated by spectral reflectance, Remote Sens. Environ., 14, 65-75, 1984.

Higgins, M. A., Asner, G. P., Perez, E., Elespuru, N., Tuomisto, H., Ruokolainen, K., and Alonso, A.: Use of Landsat and SRTM Data to Detect Broad-Scale Biodiversity Patterns in Northwestern Amazonia, Remote Sens., 4, 2401-2418, 2012.

Hodkinson, I. D.: Terrestrial insects along elevation gradients: species and community responses to altitude, Biol. Rev., 80, 489513, doi:10.1017/S1464793105006767, 2005.

Huaraca Huasco, W., Girardin, C. A. J., Doughty, C. E., Metcalfe, D. B., Durand, L., Silva-Espejo, J. E., Galiano Cabrera, D., Aragao, L. E. O., Rozas Davila, A., Marthews, T. R., HuaracaQuispe, L. P., Alzamore-Taype, I., Eguiluz-Mora, L., Farfán, W., Cabrera, K. G., Halladay, K., Salinas-Revilla, N., Silman, M., and Malhi, Y.: Seasonal production, allocation and cycling of carbon in two mid-elevation tropical montane forest plots in the Peruvian Andes, Plant Ecol. Div., 7, 125-142, 2014.

Kellner, J. R. and Asner, G. P.: Convergent structural responses of tropical forests to diverse disturbance regimes, Ecol. Lett., 12, 887-897, doi:10.1111/j.1461-0248.2009.01345.x, 2009.

Kokaly, R. F., Asner, G. P., Ollinger, S. V., Martin, M. E., and Wessman, C. A.: Characterizing canopy biochemistry from imaging spectroscopy and its application to ecosystem studies, Remote Sens. Environ., 113, S78-S91, doi:10.1016/j.rse.2008.10.018, 2009.

Lawton, R. O.: Canopy gaps and light penetration into a windexposed tropical lower montane rain forest, Canadian Journal of Forest Research, 20, 659-667, 1990.

Lefsky, M. A., Cohen, W. B., Acker, S. A., Parker, G. G., Spies, T. A., and Harding, D.: Lidar remote sensing of the canopy structure and biophysical properties of Douglas-fir western hemlock forests, Remote Sens. Environ., 70, 339-361, 1999.

Lefsky, M. A., Cohen, W. B., Parker, G. G., and Harding, D. J.: Lidar remote sensing for ecosystem studies, BioScience, 52, 1930, 2002.

Lieberman, D., Lieberman, M., Peralta, R., and Hartshorn, G. S.: Tropical forest structure and composition on a large-scale altitudinal gradient in Costa Rica, J. Ecol., 84, 137-152, 1996. 
Malhi, Y., Silman, M., Salinas, N., Bush, M., Meir, P., and Saatchi, S.: Introduction: Elevation gradients in the tropics: laboratories for ecosystem ecology and global change research, Glob. Change Biol., 16, 3171-3175, doi:10.1111/j.1365-2486.2010.02323.x, 2010.

Moser, G., Leuschner, C., Hertel, D., Graefe, S., Soethe, N., and Iost, S.: Elevation effects on the carbon budget of tropical mountain forests (S Ecuador): the role of the belowground compartment, Glob. Change Biol., 17, 2211-2226, doi:10.1111/j.13652486.2010.02367.x, 2011.

Myneni, R. B., Ramakrishna, R. N., and Running, S. W.: Estimation of global leaf area index and absorbed PAR using radiative transfer models, IEEE T. Geosci. Remote Sens., 35, 1380-1393, 1997.

Peacock, J., Baker, T. R., Lewis, S. L., Lopez-Gonzalez, G., and Phillips, O. L.: The RAINFOR database: monitoring forest biomass and dynamics, J. Veg. Sci., 18, 535-542, doi:10.1111/j.1654-1103.2007.tb02568.x, 2007.

Quesada, C. A., Phillips, O. L., Schwarz, M., Czimczik, C. I., Baker, T. R., Patiño, S., Fyllas, N. M., Hodnett, M. G., Herrera, R., Almeida, S., Alvarez Dávila, E., Arneth, A., Arroyo, L., Chao, K. J., Dezzeo, N., Erwin, T., di Fiore, A., Higuchi, N., Honorio Coronado, E., Jimenez, E. M., Killeen, T., Lezama, A. T., Lloyd, G., López-González, G., Luizão, F. J., Malhi, Y., Monteagudo, A., Neill, D. A., Núñez Vargas, P., Paiva, R., Peacock, J., Peñuela, M. C., Peña Cruz, A., Pitman, N., Priante Filho, N., Prieto, A., Ramírez, H., Rudas, A., Salomão, R., Santos, A. J. B., Schmerler, J., Silva, N., Silveira, M., Vásquez, R., Vieira, I., Terborgh, J., and Lloyd, J.: Basin-wide variations in Amazon forest structure and function are mediated by both soils and climate, Biogeosciences, 9, 2203-2246, doi:10.5194/bg-9-2203-2012, 2012.

Raich, J. W., Russell, A. E., and Vitousek, P. M.: Primary productivity and ecosystem development along an elevational gradient on Mauna Loa, Hawaii, Ecology, 78, 707-722, 1997.

Regard, V., Lagnous, R., Espurt, N., Darrozes, J., Baby, P., Roddaz, M., Calderon, Y., and Hermoza, W.: Geomorphic evidence for recent uplift of the Fitzcarrald Arch (Peru): A response to the Nazca Ridge subduction, Geomorphology, 107, 107-117, 2009.

Roberts, D. A., Green, R. O., and Adams, J. B.: Temporal and spatial patterns in vegetation and atmospheric properties from AVIRIS, Remote Sens. Environ., 62, 223-240, 1997.
Sellers, P. J., Los, S. O., Tucker, C. J., Justice, C. O., Dazlich, D. A., Collatz, G. J., and Randall, D. A.: A global $1^{\circ}$ by $1^{\circ}$ NDVI data set for climate studies. Part 2: The generation of global fields of terrestrial biophysical parameters from the NDVI, Int. J. Remote Sens., 15, 3519-3545, 1995.

Silman, M. R.: Plant species diversity in Amazonian forests, in: Tropical rain forest responses to climate change, edited by: Bush, M. and Flenly, J., Springer-Praxis, London, 2006.

Tanner, E. V. J., Vitousek, P. M., and Cuevas, E.: Experimental investigation of nutrient limitation of forst growth on wet tropical mountains, Ecology, 79, 10-23, 1998.

Terborgh, J.: Maintenance of diversity in tropical forests, Biotropica, 24, 283-292, 1992.

Ticehurst, C., Held, A., and Phinn, S.: Integrating JERS-1 imaging radar and elevation models for mapping tropical vegetation communities in Far North Queensland, Australia, Photogramm. Eng. Rem. S., 70, 1259-1266, 2004.

Tuomisto, H., Ruokolainen, K., Kalliola, R., Linna, A., Danjoy, W., and Rodriquez, Z.: Dissecting Amazonian biodiversity, Science, 269, 63-66, 1995.

Ustin, S. L., Roberts, D. A., Gamon, J. A., Asner, G. P., and Green, R. O.: Using imaging spectroscopy to study ecosystem processes and properties, Bioscience, 54, 523-534, 2004.

Vitousek, P. M., Matson, P. A., and Turner, D. R.: Elevational and age gradients in Hawaiian montane rainforest: foliar and soil nutrients, Oecologia, 77, 565-570, 1988.

Vitousek, P. M., Aplet, G., and Turner, D.: The Mauna Loa environmental matrix: foliar and soil nutrients, Oecologia, 89, 372-382, 1992.

Wessman, C. A., Nel, E. M., Bateson, C. A., and Asner, G. P.: A method to access absolute fIPAR of vegetation in spatially complex ecosystems, Proceedings of the Seventh Airborne Earth Science Workshop, NASA Jet Propulsion Laboratory, Pasadena, CA, 409-418, 1998.

White, E. P., Enquist, B. J., and Green, J. L.: On estimating the exponent of power-law frequency distributions, Ecology, 89, 905912, 2008. 